\title{
Da ilha-refúgio ao espaço da xenofobia, num «arquipélago» de ambiguidade, na tragédia Les portugaiz infortunez, de Nicolas-Chrétien Des Croix (1608)
}

From an island-refuge to a xenophobic space, in an «archipelago» of ambiguity, in the tragedy Les portugaiz infortunez, by Nicolas-Chrétien Des Croix (1608)

\author{
António Manuel de Andrade Moniz ${ }^{1}$
}

Resumo: Utilizando o contributo teórico de autores como G. Voisset e Massimo Cacciari, além do de poetas como Horácio, Fernando Pessoa e Édouard Glissant, este estudo analisa a tragédia Les portugaiz infortunez, de Nicolas-Chrétien Des Croix, publicada em Rouen, em 1608. 0 naufrágio de Manuel de Sousa Sepúlveda, com sua mulher e filhos, além de 600 tripulantes e passageiros, no Galeão S. João, em 1552, na Terra do Natal, relato publicado na época em avulso e compilado no T. I da História trágico-marítima (1735), por B. Gomes de Brito, bebido na fonte do Historiarum indicarum (Livro XVI) do padre G. Maffei (Florença, 1588) é o objeto da peça trágica. Após a peregrinação pelo litoral e pelo sertão, envolvendo cerca de 300 léguas, os náufragos são acolhidos na ilha do Inhaca por um régulo bom. Mas a desconfiança dos Portugueses leva-os a um imprudente afastamento da ilha até chegarem a Manhiça, onde são desarmados e desnudados, morrendo de exaustão e fome a maior parte deles. Finalmente, partem da itha dos Elefantes para a ilha de Moçambique. À imagem da ilha-refúgio (Inhaca, Elefantes, Moçambique) sucede as da xenofobia, da desconfiança e do sacrifício expiatório. A imagem do «arquipélago», extensiva ao espaço continental (Manhiça), envolve de ambiguidade a receção aos náufragos que na peça são avaliados também no âmbito da ambiguidade: ambição colonialista versus anúncio evangélico.
Palavras-chaves: Ilha; arquipélago; refúgio; xenofobia; ambiguidade; catarse.

Abstract: This paper applies theory concepts by G. Voissset and Massimo Cacciari, but also the contribution of poets like Horatio, Fernando Pessoa and Édouard Glissant. It is an analysis of the tragedy Les portugais infortunez, by Nicolas-Chrétien Des Croix, edited in Rouen (1608). The shipwreck of Manuel de Sousa Sepulveda with his wife and children but also 600 people in Galion S. João in 1552, in South Africa (Terra do Natal), account edited in 1554 and compiled by Bernardo Gomes de Brito (Tragic history of the sea, T. I, 1735) which source is Historiarum indicarum (B. XVI) by father G. Maffei (Florence, 1588 ) is the theme of this tragic play. After six months of pilgrimage in Africa (300 leagues) the Portuguese are welcome in Inhaca island by a good king. But their imprudence pushes them to Manhiça, another island where they are disarmed and denuded till their death by exhaustion and hunger the majority of them. Finally, they leave the Elephant island to arrive to Mozambique island. From the image of island refuge (Inhaca, Elephant, Mozambique) it succeeds the xenophobia, suspicion and expiatory sacrifice. The image of archipelago is ambiguous: the wrecked persons are ambitious but also annunciators of the Gospel.

Keywords: Island; archipelago; refuge; xenophobia; ambiguity; catharsis.

${ }^{1}$ CHAM/Universidade Nova de Lisboa. 


\section{Introdução}

Neste artigo, recorremos à tragédia Les portugaiz infortunez, de Nicolas-Chrétien Des Croix, publicada em Rouen, em 1608, para ilustrar a nossa reflexão sobre a imagem de ilha-refúgio, no contexto teórico do imaginário de arquipélago e arquipelização.

A interação entre o sujeito e o espaço domina a nossa vida e a poética do imaginário releva-a na literatura como uma das categorias da narrativa e do drama.

Na peça em questão, exploraremos essa categoria como uma das expressões dominantes da expiação trágica dos protagonistas, náufragos emblemáticos da chamada História trágico-marítima.

\section{A imagem de ilha-refúgio no con- texto da arquipelização}

Em La poétique de l'espace (1957), Gaston Bachelard explora a simbologia de determinados espaços no imaginário poético, principalmente francês, em estreita ligação com o arquétipo profundo do inconsciente psíquico: «Le poète, en la nouveauté de ses images, est toujours origine de langage [...] la poésie est, plutôt qu'une phénoménologie de l'esprit, une phénoménologie de l'âme» (Bachelard, 1957: 4). Entre as imagens analisadas situam-se as da casa e do universo, as da gaveta, do cofre e do armário, do ninho, da concha, da miniatura, dos cantos, da imensidade íntima, da dialética do exterior e do interior, da esfera.
O seu discípulo Gilbert Durand desenvolve esta linha metodológica do seu mestre, em Les structures antrhopologiques de l'imaginaire (1984). Para além da análise das imagens ligadas ao tempo, explora também a dimensão do espaço fantástico e do espaço físico. Contrariando a desvalorização cultural do imaginário no pensamento oficial do Ocidente, entronca na antropologia a base pedagógica do humanismo de vocação ontológica (Durand, 1984: 493 e 498). Resgatando o mito dos Argonautas, faz Orfeu, símbolo da poesia, acompanhar como piloto, a nau de Jasão, na demanda do velo de ouro: «Aussi l'imaginaire, bien loin d'être vaine passion, est action euphémique et transforme le monde selon l'Homme de Désir [...]. Que seraient les Argonautes sans la lyre d'Orphée? Qui donnerait la cadence aux rameurs? Y aurait-il même une Toison d'Or?» (Durand, 1984: 501).

Na sequência de Michel Foucault, Henri Léfèbvre e Mikhail Bakhtine, o estudo do espaço literário tem vindo a adquirir uma dimensão crescente no domínio da teoria literária, numa perspectiva de transgressão geral das normas estabelecidas.

Maurice Blanchot (1988) confere ao espaço literário um lugar específico na criação do objecto literário, enquanto Franco Moretti (2000) estabelece uma relação entre texto e espaço.

Por sua vez, o geógrafo americano Edward Soja (1996) identifica um terceiro espaço 
(thirdspace), entre o espaço físico e o literário, numa referencialidade entre o mundo e o texto, entre referente e representação.

Bertrand Westphal (2005), distanciando-se do olhar colonialista, que considera monolítico, subjetivista e eurocêntrico, apresenta, em alternativa, uma poética a que chama de arquipélago, na linha de Massimo Cacciari (1997), segundo o qual o espaço humano é concebido como um conjunto «di kósmoi, strutture dotate d'ordine e dialogante tra loro» (Cacciari, 1997: 19), através do quadro teórico da geocrítica:

La géocritique correspondrait bel et bien à une poétique de l'archipel, espace dont la totalité est constitué par l'articulation raisonnée de tous les îlots - mobiles - qui le composent. De tous les espaces, l'archipel est le plus dynamique. [...] Là où l'espace est archipel, les identités culturelles se compliquent au point de rester à tout jamais définissables, et donc indéfinies. [...] tout l'espace, par-dessous la surface de l'évidence, est archipel. [...] Toute identité est elle-même plurielle; toute identité est archipel. (Westphal, 2005: 15)

Bebendo em Deleuze e Guattari, a noção de reterritorialização (1980: 635) (o território seria «un tenir-ensemble déléments hétérogènes» (398)), apresenta o espaço segundo Youri Lotman, como «ce mélange hétérogène fonctionnant comme un tout» (Lotman, 1999: 147).

Deste modo, a geocrítica, combinando a relação espácio-temporal, a transgressividade e a referencialidade, permitiria traçar uma espécie de cartografia ficcional dos espaços humanos (Westphal, 2005: 36).

Herdando esta noção geo-espacial de arquipélago, Georges Voisset emprega o neologismo «archipélisation» como «expression de désirs contradictoires, une archipélisation comme concept médian entre l'un continental et la projection insulaire de cet Un» (Voisset, 2003: 13), utilizando a expressão «tension archipélique» para designar a eterna busca da juventude: «être alors la tension archipén lique vers nos devenirs est-elle la nouvelle formule secrète d'une éternelle quête de jouvence» (Voisset, 2003: 16). Assim, a imagem arquetípica da Atlântida significaria o mito insular da utopia: «L'Utopie pourrait paraître moins pénétrée d'eau que l'Atlantide. Le nom de son fleuve principal, Anhydre, pourrait même paraître suspect, avec un préfixe privatif (sans eau). Mais bien il a bien une source» (Voisset, 2003: 30). 0 arquipélago representaria, deste modo, um lugar de encontro de povos: «des lieux de rencontre de peuples, de races, de civilisations, qui portent avec eux des temps et des intensités de vie différentes» (Voisset, 2003: 57).

A imagem de ilha-refúgio já está patente no Epodo XVI, de Horácio, no qual exorta os Romanos dignos desse nome à fuga ("Etrusca praeter et uolate litora» - 16,40) para as ilhas míticas dos Bem-Aventurados («arua beata / petamus, arua diuites et insulas» - 16,41-42), em face da ruína («ipsa Roma [...] ruit» - 16, 
2) desencadeada pelas guerras civis («bellis ciuilibus» - 16, 1). Essas ilhas representam o arquétipo do quadro idílico de uma nova idade de ouro («tempus aureum» - 16, 64), simbolizado na fertilidade da terra e do gado e na ausência de animais ferozes e doenças letais (cf. 16, 43-52.61).

É este quadro utópico que voltamos a encontrar nos relatos medievais das ilhas dos Bem-Aventurados, como, nas lendas célticas, a Ilha de Avalon, ou Ilha Branca do Norte, ou de Vidro (Leuké), e na obra de Thomas More (Utopia), já no Renascimento. A própria Carta do achamento do Brasil, de Pêro Vaz de Caminha (1500) representa a terra encontrada e a ingenuidade do Índio como sinais dessa utopia.

Em 1952, o poeta antilhano Édouard Glissant celebra «un champ d'îles non inventées», «parfaisant le souvenir et l'espoir» (Glissant, 1994: 1), um arquipélago-refúgio de náufragos:

L'île entière est une pitié

Qui sur soi-même se suicide

Dans cet amas d'argiles ruées

Ô la terre avance ses vierges

Apitoyée cette île et pitoyable

Elle vit de mots dérivés

Comme un halo de naufragés

À la rencontre des rochers

(Glissant, 1994: 2)

$\mathrm{Na}$ Mensagem, Fernando Pessoa evoca «As ilhas afortunadas» como um espaço utópico, comunicado na voz que «nos diz a esperança», mas só tem lugar no nosso imaginário:

\author{
São ilhas afortunadas, \\ São terras sem ter lugar, \\ Onde o Rei mora esperando. \\ Mas, se vamos despertando, \\ Cala a voz, e há só o mar \\ (Pessoa, 1978: 86)
}

Semelhante demitização se verifica no poema «Não sei se é sonho, se realidade», no qual se evoca uma «terra de suavidade / Que na ilha extrema do sul se olvida», «uma mistura de sonho e vida», onde «A vida é jovem e o amor sorri», mas desvirtuada pelo próprio sonho, pois «Só de pensá-la cansou pensar», onde, afinal, «O mal não cessa, não dura o bem»:

\footnotetext{
Não é com ilhas do fim do mundo, Nem com palmares de sonho ou não, Que cura a alma seu mal profundo. Que o bem nos entra no coração. É em nós que é tudo. É ali, ali, Que a vida é jovem e o amor sorri (Pessoa, 1995: 158)
}

\section{Les portugaiz infortunez}

Nicolas-Chrétien Des Croix, nascido em Argentan, perto de Rouen, onde terá estudado teatro, publicou quatro tragédias em Rouen: Rosemonde (1603), Les portugaiz infortunez, Amnon et Thamar e Alboin (1608), bem como a tradução da pastoral italiana Ravissement de Cefale, de Gabriel Chiabrera, em cinco atos, primeiramente representada em Florença em 
1600, nas bodas reais de Henrique IV e Maria de Médicis, dedicada ao Delfim em 1608, e Les amants ou la grande pastorelle, em 1613, com notória celebridade ao longo do século XVII.

A peça Les portugaiz infortunez, em cinco atos, exemplifica o realismo cénico do teatro barroco, surpreendendo críticos em épocas posteriores, como La Vallière (1768), Solleine (1843) e Vavasseur (1892), pela nudez da representação,e Raymond Lebègue (1977), pelo macabro (Hardee, 1991: 7). Criticando a limitação de algumas destas análises, Hardée sublinha a originalidade da peça no quadro dos novos horizontes abertos pela volumosa literatura geográfica da época, iniciando o confronto entre o mundo europeu e o exótico, o primeiro tido como superior em face do outro (Hardee, 1991: 8).

Dedicada a Claude du Bellay, Abbé de Savigny, a tragédia Les portugaiz infortunez põe em cena o drama dos sobreviventes do naufrágio do Galeão Grande S. João, na Terra do Natal, em 1552, cujos protagonistas, além de 600 Portugueses e escravos, são o Capitão da Índia Manuel de Sousa de Sepúlveda (na peça, Sose), sua esposa D. Leonor de Sá (Eleonor), filha do governador Garcia de Sá, seus filhos, e o cunhado Pantaleão de Sá. O relato foi publicado na época em avulso e compilado no T. I da História trágico-marítima (1735), por B. Gomes de Brito (Moniz, 2001), mas bebido por Des Croix na fonte do Historiarum indicarum, (Livro XVI) do padre G. Maffei (Florença, 1588), escrito em latim, como é apontado pelo autor no «Sujet de la tragédie». Após a peregrinação pelo litoral e pelo sertão, envolvendo cerca de 300 léguas, os náufragos são acolhidos na ilha da Inhaca por um régulo bom. Mas a desconfiança dos Portugueses leva-os a um imprudente afastamento da Ilha até chegarem a Manhiça, onde são desarmados e desnudados, morrendo de exaustão e fome a maior parte deles. Finalmente, partem da ilha dos Elefantes para a ilha de Moçambique.

Apresentando oito personagens entre os Brancos e igual número entre os Negros, o Coro das Moças portuguesas contrasta com o Coro das africanas, chamadas Etíopes.

O Prólogo faz intervir outro par contrastivo, desta vez entre as personagens mitológicas: o Génio do Cabo da Boa Esperança, a quem Camões chamou Adamastor versus o Arcanjo Rafael, patrono da nau de Paulo da Gama. Tal como o Velho do Restelo e Adamastor n'Os Lusíadas, o Génio critica a ambição do colonialismo português, ameaçando com o naufrágio e outros castigos Bartolomeu Dias, D. Francisco de Almeida, Américo Vespúcio, Fernão de Magalhães e Afonso de Albuquerque, o leão-do-mar:

O folle ambition que tu causes de maux! Sous couleur de chercher je ne sçay quels metaux Tu rends foible d'honneur des legitimes princes, De pestilens discords tu remplis leurs provinces, Tu changes des humains le naturel benin, Et leur fais avaller un deguisé venin (Croix, 1991: 49) 
Por sua vez, o Arcanjo Rafael exalta o projeto missionário português (Croix, 1991: 52), bem como a memória épica, a morte gloriosa e a bem-aventurança da Virtude (Croix, 1991: 54).

O I Ato, com as intervenções do piloto André Vaz (Vasco), de Pantaleão de Sá, do Coro português e do pontífice sarraceno, depois de elogiar o tópico clássico da aurea mediocritas (Croix, 1991: 57-58) e a arte náutica (Croix, 1991: 59), alimenta a esperança do encontro de alimento (Croix, 1991: 61), enquanto é feito um inquérito aos estrangeiros sobre a sua origem e proveniência, numa autoidentificação contrastiva com o Outro (Croix, 1991: 63), na qual sobressai a religião (Croix, 1991: 64-65). Perante a estranheza do pontífice sarraceno pelas invenções europeias (espelhos e relógios), surge a desconfiança e a traição mourisca, terminando o Ato com a manifestação do receio pelos perigos das viagens marítimas e a inconstância da roda da Fortuna (Croix, 1991: 69).

O II Ato, fazendo intervir Serif, lugar-tenente do rei de Manhiça (Manique), Tavar, senhor da região, o Coro dos Etíopes, Sousa, André Vaz, Pantaleão e o Coro português, apresenta os estrangeiros como ladrões avaros (Croix,1991: 71), enquanto se manifesta a oposição às conquistas e construção de fortalezas, e Sousa se penitencia do seu pecado (Croix, 1991: 72), lamentando a fragilidade humana (Croix, 1991: 81), em contraste com a exaltação da constância e a dignidade no sofrimento (Croix,
1991: 81). O Ato termina com a denúncia da avareza e da cupidez náuticas, castigadas pelo naufrágio, e a proscrição do ouro, como no final dos cantos IV e VIII d'Os Lusíadas.

No III Ato, domina a estratégia do desarmamento dos estrangeiros como astúcia do seu domínio, em nome da lei, em contraste com a desconfiança e o receio de D. Leonor (Croix, 1991: 108).

O IV Ato põe frente a frente D. Leonor e a raf inha Melinde. Esta, depois de elogiar o marido, aceita, a troco da oferta de um relógio (Croix, 1991: 124) ajudar os estrangeiros. Pantaleão narra a aventura de quatro meses de errância dos 120 sobreviventes dos 600 náufragos, não deixando de elogiar o régulo bom, que os acolhera na ilha de Inhaca (Croix, 1991: 121-122), em contraste com o de Manhiça, terminando o Ato com o desnudamento de D. Leonor e suas imprecações (Croix, 1991: 131) interpretado pelo Coro português como uma terrível punição (Croix, 1991: 132-134).

O clímax trágico virá no último Ato, com a catástrofe que submerge os protagonistas portugueses: a morte da família Sepúlveda, primeiro o filho mais novo, depois a mãe e, finalmente, o pai (Croix, 1991: 155-156 e 163). No entanto, da catástrofe brota o anúncio de nova caminhada, rumo à libertação, feito pelo piloto e por Pantaleão, à semelhança de Israel, após a libertação do cativeiro do Egipto: «Or acheminons-nous et rendons toute peine, / 
Le rivage aborder de la mer plus prochaine» (Croix, 1991: 164).

A lei clássica das três unidades faz com que a ação seja concentrada numa jornada, num só lugar: em Manhiça, onde se dá a expiação dos náufragos, o seu desarmamento e a morte dos protagonistas. Manhiça é, pois, o lugar cimeiro da cátharsis dos náufragos, após quatro meses de errância e fome.

Apesar do ponto de vista anticolonialista de Des Croix, não faltam as referências positivas às personagens que, vítimas do Destino, são objeto da sua peça trágica, e merecem o seu olhar piedoso, como expressa no «Sujet de la tragédie»:

Ceux qui restent en vie combatus, \& demi morts de faim, de soif, \& de tristesse, en vn pays sablonneux, \& inculte, acablez de frayeur, \& de vergongne, stupides pour voir vne reuolution si étrange, \& indigne : baissent les yeux en terre, n'osant de honte se regarder l'vn l'autre. Eleonor Femme honorable, se souuenant de sa Race, voyant ces Barbares dépouiller son Mary, ses Enfans, \& Elle, oubliant son sexe, \& sa dignité, les prouoque à coups de poin, \& de souflets, les irritant par tous les moyens pour la tuer. Ils la laissent comme les autres toute nue. Cette chaste Dame à qui la lumière aporte plus d'horreur \& de tristesse que la Mort, s'enterre dans du sable, \& pour couurir ce qui se peut voir de sa chair nue, confusément épand ses cheveux sur ses épaules, \& sa poitrine. Vne profonde tristesse serre de douleur le cœur, \& la bouche de Sose, si bien qu'il est comme frapé d'vn esclat de foudre, ou comme vne statuë. Le soin de ses Enfans, $\&$ de sa Femme le reueille tout à coup, puis s'en va dans vne prochaine forest chercher quelque nourriture. De retour, il treuue le plus petit de ses Fils decedé, \& sa Femme qui auoit esté trois jours sans boire, ny manger, toute acablée de tristesse, \& de larmes. Il retourne à la queste: Reuenu, il void sa Femme, \& son autre Fils expirez, \& les Seruantes à grans cris se lamenter autour de ces poures Corps. Il fait retirer ces Femmes, puis se iette par terre apuyé quelque temps sur le bras droit estendu de sa Femme trépassée, qu'apres, à l'aide des seruantes, il enfouïlle dans le sable, \& son Enfant aussi, sans proferer vne seulle parole. Il retourne dans la forest, ou quelque animal sauuage le deuore, n'ayant depuis esté veu. Le reste de cette poure Troupe (enuiron cent) errans vagabonds par diuerses aduentures reduits à vingtsix, sont pris Esclaues, $\&$ rachetez, par vn Pilote Portugais, qui pour acheter de l'yuoir en cette contree, estoit parti de Mosambique. Entre ceux là fut Pantaleon Sala, qui mourut depuis à Lisbonne d'vne apoplexie. Voilà le triste succez de la fortune de Sose, ou ses vertus, \& de d'Eleonor sa Femme reluisent. (Croix, 1991: 42)

O Rio Espírito Santo, designado por Des Croix como «Riuiere que Laurens Marchese Portugaiz auoit autrefois découuerte, \& nommee, du saint Esprit»(Croix, 1991: 41), é, na peça associado ao colonialismo pelo rei de Manhiça : «fleuve qui ceint ma terre / Du costé du Midi, que d'un nom bien biserre / Ils appellent grossiers du saint Esprit» (Croix, 1991: 88). Os montes de Manhiça, segundo o régulo, constituem um impedimento geopolítico à invasão 
dos estrangeiros: "Ces mots de Manica qui menassent les nuës / Du costé d'Orient ems peschent leurs venuës» (Croix, 1991: 88).

Deste modo, a xenofobia impera em Manhiça, em contraste com o bom acolhimento dispensado aos Portugueses pelo régulo da ilha de Inhaca, na sequência das tradicionais relações comerciais, acolhimento reconhecido por Pantaleão, o qual lamenta a insensata decisão de rejeitar tal acolhimento:

Un roy doux et benin nous reçoit debonnaire, Qui nous veut retenir comme à son ordinaire: D'effet, quelques marchands de nostre nation Le commerce avoient eu dedans sa region. Il nous cherist, nous aime, et promet assistance Contre ceux qui voudroient nous aporter nuisance.

Quand il nous eut chez luy bien reçeus et traitez, Ses païs nous avons contre son veil quitez, Sose croiant treuver quelques nefs portugaises Venant ou de l'Europe, ou des terres indoises. Ce bon Prince, Alagos est le nom de ce Roy, D'un naturel courtois et d'une entiere foy, Voyant nostre dessein de quiter sa demeure, Tasche de nous retenir ; pieux, il nous assure Qu'un roy de là n'est loin au brigandage né, Bien plus que lui puissant à tout mal destiné. Que puis qu'en son païs ne restons davantage, Nous gardons d'aborder un terroir si sauvage, Et tant plus nous estions priez de demeurer, Tant plus Sose vouloit instamment demarer, Doutant que souz le miel de tant de courtaisie Il n'y eust quelque fiel de mal, et perfidie, «Comme la trahison se loge plus souvent
Dans ceux qui ne vont pas les loix de Christ suivant

(Croix, 1991: 121-122)

\section{Conclusão}

À imagem da ilha-refúgio (Inhaca, Elefantes, Moçambique) sucede as da xenofobia, da desconfiança e do sacrifício expiatório. A imagem do «arquipélago», extensiva ao espaço continental (Manhiça), envolve de ambiguidade a receção aos náufragos que na peça são avaliados também no âmbito da ambiguidade: ambição colonialista versus anúncio evangélico.

\section{Bibliografia}

Bachelard, G. (1957). La poétique de l'espace. PUF. Paris;

Blanchot, M. (1988). L'espace littéraire. Gallimard. Paris;

Brito, B.G. (1735). História tragico-marítima. Livraria d'Alcobaça. Lisboa Occidental. T. 1;

Cacciari, M. (1997). L'arcipelago. Adelphi. Milano;

Croix, N.-C. (1991). Les portugaiz infortunez. Droz. Genève;

Deleuze, G. e Guattari, F. (1980). Mille plateaux. Minuit. Paris;

Durand, G. (1984). Les structures anthropologiques de l'imaginaire. Dunod. Paris;

Flaco, O.H. (1967). Opera. Oxford Classical Texts. Oxford;

Glissant, E. (1994). Poèmes complets. Gallimard. Paris;

Hardee, A.M. (1991). Introduction. Em: N.-C. Croix, Les portugaiz infortunez. Droz. Genève;

Lebègue, R. (1977). Etudes sur le théâtre français. Nizet. Paris; 
Lotman, Y. (1999). L'univers de l'esprit. Pulim. Limoges;

Maffei, G. (1588). Historiarum indicarum, liber $X V I$. Firenze;

Moniz, A.M.A. (2001). A História trágico-marítima: Identidade e condição humana. Edições Colibri. Lisboa;

Moretti, F. (2000). Atlas du roman européen: 1800-1900. Seuil. Paris;

Pessoa, F. (1978). Mensagem. (12. ${ }^{a}$ ed.). Ática. Lisboa;

Pessoa, F. (1995). Poesias. (15. a ed.). Lisboa: Ática;
Soja, E. (1996). Thirdspace: Journeys to Los Angeles and other real-and-imagined places. Basil Blackwell. Oxford;

Solleine, M. (s. d.). Bibliothèque dramatique. Burt Franklin. New York;

La Vallière, Duc de (1768). Bibliothèque du théâtre français depuis son origine. Groell. Dresden;

Voisset, G. (2003). L'imaginaire de l'archipel. Éditions Karthala. Paris;

Westphal, B. (2005). Geocritique, mode d'emploi. Pulim. Limoges. 